\title{
A Study on the Expected Retirement Age Prediction of 1049 Nurses and the Influencing Factors of Delayed Retirement Intention
}

\author{
Shuping Zhou1 ${ }^{1}$, Yunsuo Gao ${ }^{*}$, Xiaodan Wang ${ }^{2}$, Min Guo ${ }^{1}$ \\ ${ }^{1}$ Hainan General Hospital, Haikou, China \\ ${ }^{2}$ School of Public Health, Hainan Medical University, Haikou, China \\ Email: ^yunsuogao@126.com, ZHOUSHUPING@163.com
}

How to cite this paper: Zhou, S.P., Gao, Y.S., Wang, X.D. and Guo, M. (2020) A Study on the Expected Retirement Age Prediction of 1049 Nurses and the Influencing Factors of Delayed Retirement Intention. Health, 12, 1318-1331.

https://doi.org/10.4236/health.2020.129094

Received: August 9, 2020

Accepted: September 26, 2020

Published: September 29, 2020

Copyright ( 2020 by author(s) and Scientific Research Publishing Inc. This work is licensed under the Creative Commons Attribution International License (CC BY 4.0).

http://creativecommons.org/licenses/by/4.0/ (c) (i) Open Access

\begin{abstract}
The results were analyzed by unconditional logistic regression. The analysis results showed that the positions entered into the regression model ( $\mathrm{OR}=$ 2.339); the expected retirement age $(\mathrm{OR}=3.280)$; and delayed retirement can better solve the pension problem $(\mathrm{OR}=0.553)$. Retirement can relieve child financial pressure $(\mathrm{OR}=0.217)$, emotional exhaustion $(\mathrm{OR}=0.913$ ) and social opportunities ( $\mathrm{OR}=1.132)$. The $\mathrm{OR}$ of job title, expected retirement age, and social opportunities is greater than 1, and the others are less than 1. Conclusion: The most expected retirement age for nurses is 50 to 55 years old, and they are more inclined to retire early. Factors affecting the willingness to postpone retirement include position and expected retirement age. Postponement of retirement can better solve pension problems. Postponement of retirement can alleviate child financial pressure, social opportunities and emotional exhaustion.
\end{abstract}

\section{Keywords}

Nurse, Expected Retirement Age, Willingness to Delay Retirement, Influencing Factors

\section{Introduction: Willingness to Delay Retire}

Retirement age is the age limit for workers to withdraw from the human resources market due to old age and other reasons to obtain corresponding economic security [1]. According to data from the sixth national census, China's 
population of 60 years and over accounts for $13.6 \%$ of the country's total population. China has entered an aging society [2]. The Third Plenary Session of the Eighteenth Central Committee of the Communist Party of China pointed out that an implementation plan for delaying the retirement age will be proposed in 2020. The implementation plan for delaying the retirement age will be put forward, and the "gradual delay of retirement" will be implemented. The reform plan aims to solve many problems such as increasing population aging, rising labor costs, reducing demographic dividends, and pension deficits in my country's economic development [3].

Extending the retirement age and providing better benefits after retirement can make up for the talent and financial gaps caused by aging, and it can also allow retired elderly people to play their residual heat. Delaying retirement can be said to be a matter of far-reaching significance for both the country and the people. However, in real life, different interests and needs make different social roles have different views and opinions on delayed retirement. The quality of nursing work is closely related to the patient's life and directly affects the patient's recovery from illness. Therefore, the investigation of nurses' willingness to delay retirement and the influencing factors should be paid more attention and attention. This study analyzes the expected retirement age prediction of 1049 nurses and the influencing factors of their willingness to delay retirement age, and provides a scientific basis for relevant departments to formulate retirement policies. It is of great significance for improving the shortage of nurses and improving the quality of care.

\section{Objects and Methods}

\subsection{Object}

Since Hainan is the smallest province in China, there are only five top-three hospitals in Haikou so far (one of which is a traditional Chinese Medicine Hospital), this survey can represent the clinical nursing population of top-three hospitals in Hainan. In this survey, 4 hospitals in Grade III A of Haikou City were selected by multi-stage random sampling method. The method of stratified random sampling was adopted from 7 levels of hospitals, including internal, external, women, children, emergency, intensive-care unit and outpatient, $50 \%$ of each floor. Criteria for inclusion of samples: those who had been in clinical nursing, were willing to participate in the study and were over the age of 30; criteria for exclusion of samples: those who had been seconded to non-nursing jobs, and transferred from the cumulative time of more than 5 years.

\subsection{Survey Tools}

\subsubsection{Questionnaire on Nurses' Willingness to Delay the Retirement Age}

With reference to Yu Cuiting's survey on the willingness to delay retirement age among college teachers [4], it was added or subtracted according to the professional characteristics of nurses, and revised after the preliminary survey, totaling 
23 items. The content includes: Are you willing to postpone your retirement age, whether you are willing to continue your job, are you willing to re-employ after retirement, position, promotion space, busyness of work, family monthly net income, number of dependents, current living standards, current health circumstances, I feel that the job salary is high, I am worried that losing my original working relationship after retirement will lead to a monotonous life, the expected retirement age, delayed retirement can more effectively use human resources, delayed retirement can better solve the pension problem, delayed retirement age can relieve children Whether economic pressure, medical disturbances or medical violence affect the willingness to delay retirement, etc.

\subsubsection{Nurse Job Satisfaction Scale}

The McCloskey/Mueller Satisfaction Scale (The McCloskey/Mueller Satisfaction Scale, MMSS) [5] is currently the most widely used and has been proven to have good reliability and validity, including welfare benefits, shifts, family and work balance, Relationships between colleagues, social opportunities, opportunities to do part-time jobs, job recognition, professional development, and control and responsibility for work, totaling 31 items. According to the Likert scale five-level scoring method, it is divided into five levels from 1 to 5 , among which are very satisfied ( 5 points), relatively satisfied ( 4 points), neither satisfied nor dissatisfied (3 points), and not very satisfied ( 2 Score), very dissatisfied (1 point), the higher the score, the higher the job satisfaction.

\subsubsection{Nursing Burnout Scale (NBS) [6]}

The Nurse's Job Burnout Scale has 3 dimensions and 15 conditions, including 7 questions about emotional exhaustion; 3 questions about depersonalization; and 5 questions about less sense of accomplishment. The scores of the three dimensions are independent of each other and cannot be added. The scores of each dimension are the average score of all items in this dimension. In terms of emotional exhaustion and depersonalization, the higher the score, the stronger the degree of burnout; in the aspect of less accomplishment, the higher the score, the weaker the degree of burnout.

\subsubsection{Conduct Pre-Survey}

A pre-survey of 56 nurses in a hospital was conducted on November 2, 2015 and November 16, 2015, to check the reliability and validity of the scale, and make a preliminary analysis to increase or decrease influencing factors. The reliability of the Cronbach's coefficient of the nurse job satisfaction scale was 0.937, the split-half reliability was 0.789 , and the repeat reliability was 0.914 . The reliability of the Cronbach's coefficient of the Nurses' Burnout Scale was tested to be 0.764, the split-half reliability was 0.750 , and the repeat reliability was 0.846 . Using factor analysis to test the validity of the structure, the results show that the nurse job satisfaction scale has 8 dimensions and the nurse job burnout scale has 3 dimensions, which are consistent with the original author's entries. Therefore, each scale has high reliability and validity. 


\subsection{Data Collection}

From December 1 to 31, 2015, nurses who meet the selection criteria were selected for investigation. First, give a unified instruction, and then the head nurse of the investigation department will distribute the questionnaire collectively, and complete the questionnaire independently as required to ensure the authenticity and completeness of the questionnaire. It takes about 20 minutes. Items with missing items greater than 5 are eliminated. A total of 1100 questionnaires were distributed this time, and the unqualified questionnaires were eliminated, 1049 valid questionnaires were obtained, and the effective response rate was $93.36 \%$.

\subsection{Statistical Methods}

After summarizing the data, first encode, quantify, and assign values, and then use epidata3.0 to double-enter the data. Use SPSS19.0 statistical software for statistical analysis, use relative numbers for descriptive analysis, and compare the means of measurement data between two groups and more than two groups that obey a normal distribution (normality test uses Kolmogorov-Smirnov method), using $t$ test. And the analysis of variance, the comparison of the measurement data of the two groups and more than two groups that do not obey the normal distribution uses the rank sum test. The correlation analysis of grade data uses rank correlation analysis. The dependent variable is binary or graded data using single factor unconditional logistic regression to analyze, and the dependent variable is binary or graded data using multiple factor unconditional logistic regression (factor screening method forward condition) for factor screening, and the test level is 0.05 .

\section{Results}

\subsection{General Situation of the Research Object}

There were 1049 subjects, 31 males and 1018 females. The male to female ratio was 3:97, the average age was $37.98 \pm 7.32$ years, and the average nursing age was $17.05 \pm 8.41$ years. The analysis of the presence or absence of administrative positions showed that there were 876 nurses (83.5\%) without administrative positions, $153(14.6 \%)$ head nurses, and 20 head nurses and above (1.9\%). See Table 1 for the rest.

\subsection{Expected Retirement Age for Nurses}

A histogram is used to statistically describe the expected retirement age of nurses. The results are shown in Figure 1. The most age group is 50 - 55 years old, 659. The Kolmogorov-Smirnov method is used for normality test. The result (statistic is $0.333, P<0.001$ ), showing a skewed distribution. According to the calculation formula of the percentile of the frequency table $P_{x}=L+\frac{i}{f_{x}}\left(n \cdot x \%-F_{L}\right)$, the 
Table 1. General information questionnaire of nurses $(n=1049)$.

\begin{tabular}{|c|c|c|c|}
\hline \multicolumn{2}{|r|}{ Factor } & \multirow{2}{*}{$\begin{array}{c}\begin{array}{c}\text { Number of } \\
\text { people }(n)\end{array} \\
264\end{array}$} & \multirow{2}{*}{$\begin{array}{c}\begin{array}{c}\text { Composition } \\
\text { percentage (\%) }\end{array} \\
25.2\end{array}$} \\
\hline Department & Internal medicine & & \\
\hline & Surgery & 245 & 23.4 \\
\hline & Gynaecology & 63 & 6.0 \\
\hline & pediatrics & 54 & 5.1 \\
\hline & Emergency Department & 71 & 6.8 \\
\hline & ICU & 63 & 6.0 \\
\hline & Outpatient Department & 149 & 14.2 \\
\hline & Other & 140 & 13.3 \\
\hline \multirow[t]{4}{*}{ Marital status } & Unmarried & 93 & 8.9 \\
\hline & Married & 916 & 87.3 \\
\hline & Divorce & 34 & 3.2 \\
\hline & Widowed & 6 & 0.6 \\
\hline \multirow[t]{4}{*}{ Education level } & Below technical secondary school & 156 & 14.9 \\
\hline & Junior college & 389 & 37.1 \\
\hline & Undergraduate & 501 & 47.8 \\
\hline & Master degree or above & 3 & 0.3 \\
\hline \multirow[t]{4}{*}{ Professional title } & Nurse & 91 & 8.7 \\
\hline & Nurse & 364 & 34.7 \\
\hline & Nurse in charge & 478 & 45.6 \\
\hline & Deputy chief nurse or above & 116 & 11.1 \\
\hline \multirow[t]{3}{*}{ Post } & No & 876 & 83.5 \\
\hline & Head nurse & 153 & 14.6 \\
\hline & Head nurse and above & 20 & 1.9 \\
\hline \multirow[t]{2}{*}{ Employment status } & Staff and workers & 628 & 59.9 \\
\hline & Off staff & 421 & 40.1 \\
\hline \multirow{4}{*}{$\begin{array}{l}\text { Working with patients } \\
\text { every }\end{array}$} & Day $<50 \%$ & 30 & 2.9 \\
\hline & Contact time $50 \%-75 \%$ & 201 & 19.2 \\
\hline & $75 \%-90 \%$ & 402 & 38.3 \\
\hline & $90 \%$ above & 416 & 39.7 \\
\hline \multirow[t]{3}{*}{ Living conditions } & To live alone & 101 & 9.6 \\
\hline & Dormitory & 45 & 4.3 \\
\hline & Family living together & 903 & 86.1 \\
\hline \multirow[t]{4}{*}{ Weekly exercise time } & $<0.5$ hour & 705 & 67.2 \\
\hline & $0.5-1$ hour & 267 & 25.5 \\
\hline & $1-2$ hour & 60 & 5.7 \\
\hline & 2 above hour & 17 & 1.6 \\
\hline
\end{tabular}




\begin{tabular}{lccc} 
Continued & & & \\
\hline Personal pre tax & $<3000$ element & 93 & 8.9 \\
income (month) & $3000-5000$ element & 539 & 51.4 \\
& $5000-8000$ element & 391 & 37.3 \\
& 8000 above element & 26 & 2.5 \\
\hline
\end{tabular}

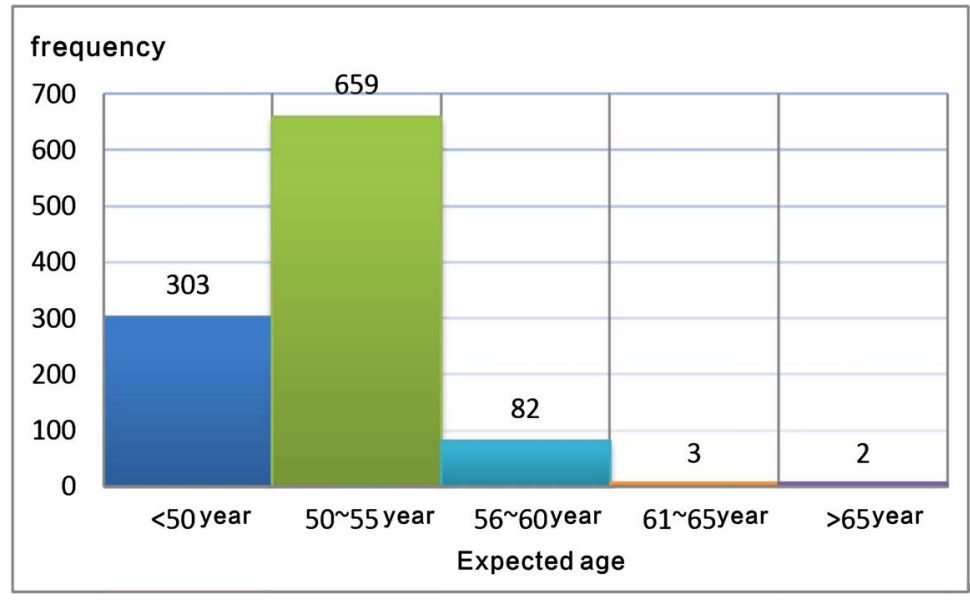

Figure 1. Histogram of retirement age expected by nurses.

median is 52.5 years old, and the $95 \%$ reference value range is $(47.5-58.0)$ years old.

\subsection{Single Factor Analysis of the Intention to Delay Retirement}

\subsubsection{Single Factor Logistic Regression Analysis of General Factors of Delayed Retirement Intention}

Taking the willingness to postpone retirement as y $(1=$ not willing; $2=$ General; 3 = willing), the promotion space, the degree of busy work, the monthly net income of family, the number of relatives under 14 years old and above 64 years old, the current living standard, the current physical health condition, the monotonous life caused by worrying about losing the original working relationship after retirement, the expected retirement age and delayed retirement can be more effective. Using human resources, delaying retirement can better solve the pension problem, and delaying retirement can relieve the economic pressure of children as independent variables, and the cumulative advantage logistic regression is used for analysis. The factors with statistical significance are shown in Table 2.

\subsubsection{Comparison of Various Dimensions and Total Scores of Job Satisfaction among Nurses Who Are Unwilling to Retire and Willing to Retire}

The $t$ test was used to compare the various dimensions and total scores of job satisfaction among nurses who were unwilling to retire and those who were willing to retire. The results showed that, except for the relationship between colleagues and the management model and work recognized, other items were statistically 
significant. The scores of delayed retirement were higher than those of unwillingness to delay retirement. The results are shown in Table 3.

\subsubsection{Comparison of Various Dimensions and Total Scores of Job} Burnout between Nurses Unwilling to Retire and Willing to Retire

The $t$ test was used to compare the various dimensions and total scores of nurses' job burnout between unwilling to retire and willing to retire. The results

Table 2. Single factor of general factors of willingness to delay retirement logisticreg ression analysis $\left(R_{\mathrm{S}}\right)$.

\begin{tabular}{|c|c|c|c|c|}
\hline project & B & Wald $\left(\chi^{2}\right)$ & $P$ & 95\%CI.OR \\
\hline Promotion space & -0.275 & 5.493 & 0.019 & $(-0.504,-0.045)$ \\
\hline Busy degree of work & 0.732 & 27.085 & 0.001 & $(0.456,1.008)$ \\
\hline Monthly net household income & 0.190 & 3.993 & 0.046 & $(0.004,0.376)$ \\
\hline $\begin{array}{l}\text { Support the number of family members under } \\
14 \text { years old or over } 64 \text { years old }\end{array}$ & -0.264 & 5.661 & 0.017 & $(-0.481,-0.046)$ \\
\hline Current living standards & 0.566 & 11.939 & 0.001 & $(0.245,0.887)$ \\
\hline Current health & -0.564 & 15.933 & 0.001 & $(-0.842,-0.287)$ \\
\hline $\begin{array}{l}\text { Worry about losing the original working } \\
\text { relationship circle after retirement and lead to } \\
\text { monotonous life }\end{array}$ & -0.604 & 8.101 & 0.004 & $(-1.010,-0.188)$ \\
\hline Expected retirement age & 1.698 & 82.268 & 0.001 & $(1.331,2.064)$ \\
\hline $\begin{array}{l}\text { Delaying retirement can make more effective } \\
\text { use of human resources }\end{array}$ & -1.183 & 25.762 & 0.001 & $(-1.640,-0.726)$ \\
\hline $\begin{array}{l}\text { Delaying retirement can better solve the } \\
\text { pension problem }\end{array}$ & -1.409 & 41.484 & 0.001 & $(-1.838,-0.980)$ \\
\hline $\begin{array}{l}\text { Delaying retirement can relieve the financial } \\
\text { pressure of children }\end{array}$ & -1.830 & 71.783 & 0.001 & $(-2.254,-1.407)$ \\
\hline
\end{tabular}

Table 3. Comparison of dimensions and total scores of nurses' job satisfaction between unwilling to retire and willing to retire $(\bar{x} \pm s)$.

\begin{tabular}{ccccc}
\hline & $\begin{array}{c}\text { unwilling } \\
(\boldsymbol{n}=946)\end{array}$ & $\begin{array}{c}\text { be willing } \\
(\boldsymbol{n}=103)\end{array}$ & $\boldsymbol{t}$ & $\boldsymbol{P}$ \\
\hline $\begin{array}{c}\text { Professional development and job control } \\
\text { and responsibility }\end{array}$ & $25.24 \pm 6.68$ & $26.68 \pm 5.98$ & -2.093 & 0.037 \\
$\begin{array}{c}\text { Satisfaction with scheduling } \\
\text { fringe benefits }\end{array}$ & $17.25 \pm 4.82$ & $18.97 \pm 5.52$ & -3.406 & 0.001 \\
$\begin{array}{c}\text { Social opportunities } \\
\text { Relationship and management model } \\
\text { among colleagues }\end{array}$ & $10.60 \pm 2.55$ & $9.17 \pm 2.30$ & -2.161 & 0.031 \\
$\quad$ Work recognized & $14.77 \pm 2.72$ & $15.08 \pm 2.57$ & -1.100 & 0.272 \\
$\begin{array}{c}\text { Opportunities for part-time jobs } \\
\text { Family and work balance }\end{array}$ & $10.47 \pm 2.15$ & $10.65 \pm 2.27$ & -0.771 & 0.441 \\
$\quad 2.24 \pm 1.07$ & $2.46 \pm 1.10$ & -1.953 & 0.05 \\
Total score of job satisfaction & $90.90 \pm 17.91$ & $97.14 \pm 17.80$ & 3.357 & 0.001 \\
\hline
\end{tabular}


showed that, except for less sense of accomplishment, the differences in other items were statistically significant, and the scores of unwillingness to delay retirement were all higher than willingness delay retirement. The results are shown in Table 4.

\subsection{Multi-Factor Analysis of Factors Affecting Nurses' Delayed Retirement Intention}

On the basis of the statistical significance of the above factors, taking into account the professional significance, the job, current health status, expected retirement age, busyness of work, and delayed retirement can better solve the pension problem, and delayed retirement can alleviate the child economy. Stress, social opportunities, and emotional exhaustion are the independent variables $\mathrm{X}$, and the willingness to postpone retirement is $\mathrm{Y}(1=$ unwilling, $2=$ willing $)$. The forward condition method is used for unconditional logistic regression analysis, in which position $(\mathrm{OR}=2.339)$, expected retirement age $(\mathrm{OR}=3.280)$ and delayed retirement can better solve the pension problem $(\mathrm{OR}=0.553)$. Delayed retirement can relieve child financial pressure $(\mathrm{OR}=0.217)$, emotional exhaustion $(\mathrm{OR}=0.929)$, and social opportunities (The $P$ values of $\mathrm{OR}=1.141$ ) are all less than 0.05 , which is statistically significant. Therefore, position, expected retirement age, and delayed retirement can alleviate child economic pressure, emotional exhaustion and social opportunities have a greater impact on nursing staff's willingness to retire. See Table 5.

Table 4. Comparison of dimensions and total scores of nurses' job burnout between unwilling to retire and willing to retire $(\bar{x} \pm s)$.

\begin{tabular}{ccccc}
\hline project & $\begin{array}{c}\text { unwilling } \\
(\boldsymbol{n}=946)\end{array}$ & $\begin{array}{c}\text { be willing } \\
(\boldsymbol{n}=103)\end{array}$ & $\boldsymbol{t}$ & $\boldsymbol{P}$ \\
\hline Emotional exhaustion & $20.41 \pm 5.12$ & $17.92 \pm 4.69$ & 4.717 & $<0.001$ \\
Less sense of achievement & $12.56 \pm 3.79$ & $12.37 \pm 4.19$ & 0.484 & 0.629 \\
De personalization & $5.79 \pm 2.51$ & $5.16 \pm 2.047$ & 2.467 & 0.014 \\
Total score of job burnout & $38.76 \pm 7.43$ & $35.45 \pm 7.94$ & 4.261 & $<0.001$ \\
\hline
\end{tabular}

Table 5. Multivariate analysis of influencing factors of nurses' retirement intention.

\begin{tabular}{|c|c|c|c|c|c|c|c|c|}
\hline Project & B & S.E. & Wald $\left(\chi^{2}\right)$ & $\mathrm{df}$ & $P$ & OR & \multicolumn{2}{|c|}{ 95\%CI.OR } \\
\hline Post $($ nothing $=1 ;$ Yes $=2)$ & 0.850 & 0.261 & 10.608 & 1 & 0.001 & 2.339 & 1.403 & 3.901 \\
\hline Expected retirement age & 1.188 & 0.201 & 34.836 & 1 & $<0.001$ & 3.280 & 2.211 & 4.867 \\
\hline $\begin{array}{l}\text { Delaying retirement can better solve the pension } \\
\text { problem (nothing }=1 ; \text { Yes }=2)\end{array}$ & -0.592 & 0.255 & 5.392 & 1 & 0.020 & 0.553 & 0.336 & 0.912 \\
\hline $\begin{array}{l}\text { Delaying retirement can relieve the financial } \\
\text { pressure of children (nothing }=1 \text {; Yes }=2 \text { ) }\end{array}$ & -1.529 & 0.253 & 36.546 & 1 & $<0.001$ & 0.217 & 0.132 & 0.356 \\
\hline Emotional exhaustion & -0.073 & 0.026 & 7.918 & 1 & 0.005 & 0.929 & 0.883 & 0.978 \\
\hline Social opportunities & 0.131 & 0.038 & 11.847 & 1 & 0.001 & 1.141 & 1.058 & 1.229 \\
\hline Constant & -2.121 & 1.041 & 4.150 & 1 & 0.042 & 0.120 & & \\
\hline
\end{tabular}




\section{Discussion}

\subsection{Nurses Are More Inclined to Retire Early}

The current retirement age for nurses is 60 for senior titles (voluntary), and 55 for intermediate and junior titles. The results of the study showed that the age group nurses expect to retire most is 50 to 55 years old, indicating that nurses are more inclined to retire early. Nurses play an extremely important role in hospitals, and the quality of their work will directly affect the quality of patients' recovery from illness. Many hospitals have a lack of nurses. Nurses have been in a tense working state for a long time. Many nurses resign due to high work pressure, which makes the lack of nurses more serious [7]. Many studies have shown that nurses are willing to resign. Don't want to work in the current hospital and nursing job [8]. If the retirement is delayed, it may strengthen the nurse's willingness to resign, leading to a more serious lack of nurses. If the retirement is delayed, it may affect the quality of nursing work and the safety of patients. Senior nurses have certain working years and experience, and have strong work competence.

The rational use of senior nurses in nursing work is a difficult point in nursing human resource management [9]. Senior seniority expects to retire at the age of 50 - 55. Hospital leaders and nursing managers should pay attention to it and take measures to intervene in these people's lives in advance. The willingness to retire early, such as increasing the training of specialist nurses, enhancing the professional ability and sense of value of nurses; enhancing communication between colleges and universities and participating in the training of students; qualified hospitals to promote the construction of a regional medical joint system, and other medical services. Institutions establish cooperative relationships, extend nursing services to families and communities, establish specialist nurse clinics, provide rehabilitation training guidance for patients in the community, etc., adopt multiple forms of jobs to attract senior nurses, and reduce the idea of early retirement. It is also a way to solve the shortage of nurses and effectively use human resources. Under the current situation of the shortage of nurses, providing conditions for nurses to voluntarily choose to postpone their retirement and increase the attractiveness of work is not only beneficial to themselves, but also a way to solve the shortage of hospital nurses.

\subsection{The Impact of General Conditions on Nurses' Willingness to Delay Retirement}

The analysis results show that the longer the age, working years and current working experience, the more willing to delay retirement. Nursing is a discipline, and nursing work is closely related to the quality of life. As a professional worker in the nursing discipline, nurses need to have professional operating skills. In clinical nursing work, elderly nurses will have difficulties with some nursing skills such as puncture, drug label checking and night shift due to physiological problems. Because elderly nurses already have high nursing professional know- 
ledge and proficient in new nursing skills In addition, he has accumulated rich experience in the management of materials and patient expenses. Based on the above factors, some hospitals will arrange elderly nurses to work relaxedly in outpatient or clinical positions, such as medical insurance management and material management. These positions have less contact time with patients, no night shifts, and the pressure and work intensity are less than those of responsible nurses. With the increase of working age, wages increase correspondingly, so nurses with long working years and elderly are more willing to delay retirement. This is similar to Yu Cui Ting et al. [4] have consistent research on college teachers. The definition of health refers to having a healthy physical and mental health, as well as good social adaptation. A healthy physique is the basic condition for human existence. Without a good body, everything is impossible to talk about. This study shows that the more busy the work and the worse the health, the stronger the willingness to delay retirement, which is consistent with common sense. The goal of nursing work is to promote and maintain people's health, but it must be on the premise that nurses should have good psychological and physical health. Nurses in the hospital to undertake a lot of nursing work, night shift rotation, long-term in a high degree of mental tension, easy to produce psychological and physical fatigue [10] such as lumbar disc herniation, muscle soreness, varicose veins, chronic fatigue and other physiological problems, anxiety, depression and sleep disorders and other psychological problems, these problems lead to the lack of enthusiasm for work, and reduce the efficiency and quality of work. Nursing work not only requires nurses to have professional knowledge and skills, but also needs to have the ability to deal with emergencies and the rotation of various shifts. Therefore, without a strong physique, they will not be competent for nursing work. If the implementation of delayed retirement, in the departments with more critical patients and serious treatment tasks, such as emergency department, ICU, etc., nurses are in high pressure and poor health for a long time, even if the nurses want to delay retirement on their subjective will, their physical condition will not allow them to carry out high-quality work tasks. Delaying retirement can effectively utilize human resources, delay retirement can better solve the pension problem, delay retirement can relieve the economic pressure of children, and there is a significant negative correlation between delayed retirement intention and delayed retirement intention. After many years of working practice, nurses have the skilled clinical nursing skills. If the value of retired nurses is reflected, they have the opportunity to continue to contribute to the society, and can also be used as one of the teaching staff for young nurses training. Delaying retirement means working longer hours and paying more pension, while shortening the number of years to receive the pension, that is, reducing the state expenditure, can solve the problem of insufficient pension. The economic income of on-the-job is higher than that of retirement, so delaying retirement can relieve the economic pressure of children. 


\subsection{The Influence of Job Satisfaction on Nurses' Willingness to Delay Retirement}

The results of univariate analysis showed that there were statistically significant differences between the six dimensions of professional development and job control and responsibility, satisfaction with shift scheduling, social opportunities, welfare benefits, part-time job opportunities, family and work balance, and nurses' willingness to delay retirement was higher than that of unwilling to delay retirement. As a clinical front-line staff, nurses are one of the most important components of the hospital, and are the main force of nursing development. Their work enthusiasm directly affects the nursing quality and organizational development [11]. Relevant studies at home and abroad show that nurses' job satisfaction is highly correlated with medical service quality, work efficiency, nurse turnover rate and patient satisfaction [12] [13] [14] [15]. Welfare is one of the important factors that determine job satisfaction. It can not only meet the basic needs of nurses' life and work, but also respect their contributions. It is a symbol of personal achievement and social status [16]. The labor intensity and risk of nursing work are increasing, but the value of nursing service is not reflected in nursing fees and nurses' remuneration. Nurses will compare their work and remuneration with others, and they will be dissatisfied with welfare treatment. Some studies have found that dissatisfaction with income is one of the main reasons for nurses' turnover [17]. To improve the job satisfaction of nurses, the primary problem is to scientifically evaluate the value of nursing services, and establish a fair and reasonable salary system and welfare system [18].

The results of multivariate analysis showed that social opportunities were the factors influencing nurses' willingness to delay retirement. With the development of economy and the improvement of living standards, the construction of nursing team is constantly strengthened and improved, and the degree of nurses is also higher and higher, and the spiritual needs are also improved. Social opportunities are necessary for human survival. One of the factors that attract nurses to delay their retirement is to get social recognition from the society, to have more opportunities to participate in social activities and to communicate with non nursing professionals. Due to the requirements of the national system, most of the families are only children, and there are not too many relatives to accompany them. Nurses expect to communicate with colleagues more after work, which is also one of the ways to reduce stress. Nurses feel that there are many opportunities for nurses to integrate into the society, and they can participate in social activities with colleagues after work, which are the factors that promote nurses' willingness to delay retirement. Therefore, more interactive activities should be carried out to enhance the cohesion among colleagues. Learning and communication is the main way for nurses to participate in continuing education. It is necessary to provide opportunities for nurses to learn and exchange, which is conducive to promoting nurses' desire for learning, instead of losing enthusiasm for their own work due to their old age. Social intercourse in- 
cludes communication with non nursing staff, so non nursing courses should be arranged in training courses, and some interest classes should be held after work.

\subsection{Effect of Job Burnout on Nurses' Willingness to Delay Retirement}

There were significant differences between emotional exhaustion, depersonalization and willingness to postpone retirement. The scores of unwilling to postpone retirement were higher than those willing to postpone retirement. Job burnout is the exhaustion state of emotion, attitude and behavior produced by individuals under long-term pressure experience [19]. This is manifested as extreme fatigue, loss of enthusiasm for work, and lack of efficiency and sense of achievement [20]. Nurses' job burnout will lead to reduced work ability and affect the quality and safety of nursing work [21]. Job stress and social conflict are mainly related to emotional exhaustion and depersonalization [22]. Some foreign studies have pointed out that medical staff lack of interpersonal communication skills, dissatisfaction with their superiors, and conflicts with colleagues are also related to job burnout [23]. The results of multi factor analysis showed that emotional fatigue was the influencing factor of delaying retirement intention, and the possible reason of fatigue was that the nursing work task of Grade-A hospital was heavy, and it was a work with high-intensity pressure, which was prone to occupational burnout [23] [24]. Most of the research objects in this study are intermediate professional titles. After years of training and clinical practice, these nurses are the business backbone of the Department and are responsible for the nursing work of critical patients. Therefore, it is easy to produce job burnout, affect the nurses' work enthusiasm and career achievement, which leads to high turnover intention.

Wang Shuhui et al. [24] research shows that there is a negative correlation between nurses' Job Burnout and social support. Having social support is effective in alleviating nurses' job burnout. Learning positive coping strategies can cope with their emotional distress, help nurses cope with pressure actively, and encourage them to face heavy work with a positive attitude. Strengthening the use of social support, improving nurses' experience of success and self achievement, encouraging and praising the progress of nurses are the key to reduce their exhaustion.

\subsection{Position has an Effect on the Intention of Delaying Retirement}

In the multi factor analysis, the results show that job, expected retirement age and delayed retirement can better solve the pension problem, and delayed retirement can alleviate the economic pressure, emotional fatigue and social opportunities of children. The OR of position, expected retirement age and social opportunity is greater than 1 , and the others are less than 1 . Studies have shown that the willingness of nursing managers to stay on duty is higher than that of nurses [25]. The higher the position, the more willing to delay retirement. High- 
er position means higher salary, recognized personal ability, more social interaction, strong personal career achievement, communication and coordination with other department personnel in the management position, and strong interpersonal communication ability. Nurses with positions belong to management posts, and the focus of their work is to monitor the quality and safety of nursing, which plays a guiding and monitoring role. They do not engage in specific nursing work, and generally do not need to work on night shift. Therefore, the nurses with high positions are willing to delay retirement.

\section{Summary}

The most expected retirement age of nurses is 50 - 55 years old, and they prefer to retire early. The influencing factors of nurses' willingness to postpone retirement include position and expected retirement age. Delayed retirement can better solve the pension problem, and delayed retirement can relieve child economic pressure, social opportunities and emotional fatigue. We should take into account the particularity of the nursing industry in order to postpone the retirement age of nurses. We should take effective measures according to the influencing factors and formulate a gradual retirement policy.

\section{Fund Project}

Innovation and entrepreneurship training program for college students of Hainan Medical College (hycx2015035). Hainan University Students' innovation and entrepreneurship training program (20160111).

\section{Conflicts of Interest}

The authors declare no conflicts of interest regarding the publication of this paper.

\section{References}

[1] Liu, H.Y. (2014) Thinking on Delaying the Retirement Age of Workers. Development Research, No. 3, 141-145.

[2] Li, Q. and Peng, H.R. (2015) Who Is More Willing to Postpone Retirement? -An Analysis of the Influencing Factors of the Elderly's Willingness to Delay Retirement in China. Journal of Public Administration, No. 2, 119-128. https://doi.org/10.1016/j.puhe.2013.08.002

[3] Tian, Z.L., Liang, X.P., Qiang, F.R., et al. (2017) Research on the Influencing Factors of Acceptance Intention of Gradual Delay Retirement Age Policy-Taking Tianjin as an Example. Scientific Decision Making, No. 1, 18-35.

[4] Yu, C.T. and Yu, J.Y. (2013) An Empirical Study on College Teachers' Willingness to Delay Retirement. Population and Development, 19, 82-89.

[5] Mueller, C.W. and McCloskey, J.C. (1990) Nurses' job Satisfaction: A Proposed Measure. Nursing Research, 39, 113-117. https://doi.org/10.1097/00006199-199003000-00014

[6] Tang, Y., Garosa, E.V.A., Lei, L., et al. (2007) Brief Introduction of NBS. Chinese Journal of Occupational Medicine, 34, 151-153.

[7] Wang, L.B., Li, Q.J., Yang, Y.M., et al. (2009) Study on the Correlation between 
Nurses' Work Values, Job Satisfaction and Turnover Intention. Chinese Journal of Nursing, 44, 495-498.

[8] Wang, C.H., Xu, J.H., Zhang, T.T.C. and Li, Q.L.M. (2020) Effects of Professional Identity on Turnover Intention in China's Hotelemployees: The Mediating role of Employee Engagement and Job Satisfaction. Journal of Hospitality and Tourism Management, 45, 10-22. https://doi.org/10.1016/j.jhtm.2020.07.002

[9] Yang, H.Y., Yan, H., Zhou, X., et al. (2013) Investigation on Turnover Intention of 721 Clinical Nurses. China Hospital, 17, 61-63.

[10] Wang, W., Wang, P.X., Zhou, X.M., et al. (2010) Correlation Analysis of Nurses' Fatigue Degree and Work Stressors. Health Research, 39, 76-78.

[11] Liu, Z.Y., Hu, Y.L., Wei, W.H., et al. (2016) Influence of Job Satisfaction on Nurses' Organizational Behavior. Modern Preventive Medicine, 43, 3387-3390.

[12] Cowin, L.S., Gracen, R.G. and Marsh, H.W. (2008) Caural Modeling of Self-Concept, Job-Satisfaction, and Retention of Nurses. International Journal of Nursing Studies, 45, 1449-1459. https://doi.org/10.1016/j.ijnurstu.2007.10.009

[13] Cai, Y.H. and Hua, J. (2014) Investigation and Analysis on Job Satisfaction of Nurses in Tertiary Class A Hospitals. Chinese PLA Journal of Nursing, 31, 9-12.

[14] Wang, Q. (2014) Investigation and Analysis on Job Satisfaction and Turnover Intention of Nurses in a Tertiary Hospital in Hangzhou. Journal of Traditional Chinese Medicine Management, 22, 842-843.

[15] Zhang, W.J., Meng, H.D., Yang, S.J. and Liu, D.P. (2018) The Influence of Professional Identity, Job Satisfaction, and Work Engagement on Turnover Intention among Township Health Inspectors in China. International Journal of Environmental Research and Public Health, 15, 988. https://doi.org/10.3390/ijerph15050988

[16] Lu, H., While, A.E. and Barriball, K.L. (2005) Job Satisfaction among Nurses: A Literature Review. International Journal of Nursing Studies, 42, 211-227. https://doi.org/10.1016/j.ijnurstu.2004.09.003

[17] Song, C.P., Feng, H., Sun, X.L., et al. (2015) Status Quo and Influencing Factors of Clinical Nursing Turnover Intention. Chinese PLA Journal of Nursing, 32, 42-45.

[18] Zheng, X.J. (2009) Study on Status Quo and Influencing Factors of Job Satisfaction of Nurses in Tertiary General Hospitals in Beijing. Peking Union Medical College, Beijing.

[19] Wang, H.M. (2014) Theory and Application of Organizational Behavior. Tsinghua University Press, Beijing, 150.

[20] Maslach, C., Schaufeli, W.B. and Leiter, M.P. (2001) Job Burnout. Annual Review of Psychology, 52, 397-422. https://doi.org/10.1146/annurev.psych.52.1.397

[21] Yan, L., Wu, D., Wu, D.Q., et al. (2015) 7 Research on the status Quo and Influencing Factors of Nurses' Professional Commitment in a Tertiary General Hospital. China Nursing Management, 15, 1436-1441.

[22] Moore, J.E. (2000) One Road to Turnover: An Examination of Work Exhaustion in Technology Professionals. MIS Quarterly, 24, 141-175. https://doi.org/10.2307/3250982

[23] Coffey, M. and Coleman, M. (2001) The Relationship between Support and Stress in Forensic Community Mental Health Nursing. Journal of Advanced Nursing, 34, 397-407. https://doi.org/10.1046/j.1365-2648.2001.01770.x

[24] Wang, S.H., Sun, M.H., Gao, H.P., et al. (2011) Relationship between Nurses' Job Stress Coping and Job Burnout. Chinese Journal of Nursing Practice and Research, 8, 16-18.

[25] Wang, J., Zhou, Y.P., Zhou, Y., et al. (2015) Status Quo and Influencing Factors of Retention Intention of Employed Nurses in a Military Hospital. Journal of Nursing Management, 15, 574-575. 